\title{
Series
}

\section{Social prescribing in very deprived areas}

\section{'I DIDN'T BECOME A GP TO SPEND MY LIFE PRESCRIBING PILLS'}

Social and medical problems are often not differentiated by patients who look to GP practices for help. Many patients present with concerns that arise from their social situation, and the management of long-term medical conditions is often affected by personal circumstances. Doctors need to be able to respond to this wider picture. Indeed, the extent to which doctors are able and willing to take into account their patients' daily lives and concerns is seen as a key element of good quality medical care by patients who live in socially deprived areas.

Many GPs develop some knowledge about resources outside of the health service that can assist patients; for example, with financial problems, domestic violence, or housing issues. Some GP practices also work with outside groups to promote or plan local resources. This practice of signposting patients to nonhealth service resources has been labelled 'social prescribing'

Ten GPs, working among some of the most deprived patient populations in Scotland, took part in a small study to examine the extent to which social prescribing forms part of their clinical work.

Two major themes emerge from this reflection. The first is their awareness of the disabling impact of government policies. The second is their aspiration to emphasise the strengths of patients themselves to tackle their own problems.

The GPs who took part are aware of the problems that many of their patients face: low pay, alienating work conditions, low expectations, poor educational achievement, ready access to drugs of addiction including alcohol and tobacco, worklessness, poor nutrition, and poor physical and mental health. Many of these factors are intergenerational and affect children from the earliest age. ${ }^{2}$

They point out that rationing on medical grounds of resources, including benefits and housing, emphasises disability. Personal anxieties and social problems are repackaged as medical problems, such as mood disorder or chronic pain. For many patients this appears to be the only channel available by which to struggle for selfbetterment.

GPs are concerned that doctors' reports provided in response to requests to prove medical need set them up as gatekeepers for social resources. Signposting patients in crisis to welfare advocates may add to this dependency if they need to emphasise that their client is a sick person in order to achieve a basic standard of living. This can create conflict between seeking to improve the patient's long-term self-efficacy, and responding to the immediate welfare needs and expectations of the patient.

Despite these concerns, the GPs recognise social prescribing as a valuable part of their practice. They believe that community resources are important in supporting the health of their patients. They also acknowledge the role of advocacy in helping patients to make better use of health services. Moreover, they express concern about the impact on their patients welfare of budget cuts to voluntary groups.

The GPs emphasise the constraints on space, time, and personnel and the need for clear boundaries as to what primary care has to offer. Many social and personal problems cannot be dealt with effectively by the GP and require community resources. Practice-attached health visitors provide an important link between the practice and the community in relation to child welfare.

The GPs do not see the role of the practice team as simply that of providing information about a list of services, but rather as using their experience and empathic relationships to support patients to make use of the most appropriate resources at the right time. Community resources are most valued by the GPs when they are seen to help people develop the positive ability to improve or take ownership' of their own health. These might include writing or creative arts groups, carers' support, volunteering, and educational opportunities as well as more traditional resources, such as addiction services or exercise schemes.

In summary, the GPs who took part in the Social Prescribing Project think it is important to help patients take control of their own health and wellbeing. They see this as a core primary care role, centred on their personal relationships with individual patients. They value other organisations that can further this goal, and regularly point patients in their direction.

The GPs believe that the following key recommendations would support more effective social prescribing in primary care:

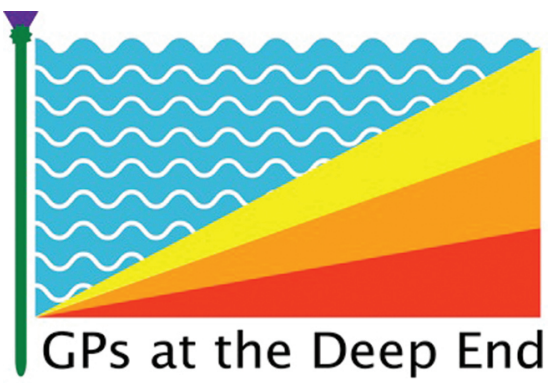

- a well-maintained, locally relevant, and user friendly internet directory of community resources for use by practitioners;

- more medical and nursing time in consultations to respond to very challenging needs by clear explanation and guidance;

- clear guidance for patients and organisations approaching GP practices for reports or advocacy support;

- extension of the primary care team to include a practice-attached social worker, employability advisor, and mental health worker;

- increased funding to voluntary and local agencies in deprived communities and protection from budgetary cuts; and

- benefits reform that reflects the realities of life in the poorest communities, and which guarantees a basic standard of living to all rather than seeking to distinguish between the deserving and the undeserving poor on medical grounds.

\section{Peter Cawston,}

On behalf of the Deep End Steering Group. This is the fifth of 12 articles from the GPs at the Deep End.

\section{DOI: 10.3399/bjgp11X572517}

\section{ADDRESS FOR CORRESPONDENCE}

\section{E-mail: p.cawstonanhs.net}

\section{REFERENCES}

1. Mercer SW, Cawston PG, Bikker AP. Quality in general practice consultations: a qualitative study of the views of patients living in an area of high socio-economic deprivation in Scotland BMC Fam Pract 2007; 8: 22

2. Deep End Report 2. Coping with needs, demands and resources. The second meeting of 'General Practitioners at the Deep End', 22 January 2010.

http://www.gla.ac.uk/media/media_146571_en .pdf laccessed 8 Apr 2011). 